\title{
Comparative life cycle assessment of first- and second-generation ethanol from sugarcane in Brazil
}

\author{
Daniel Maga ${ }^{1}$ (D) Nils Thonemann ${ }^{1} \cdot$ Markus Hiebel $^{1} \cdot$ Diogo Sebastião $^{2} \cdot$ Tiago F. Lopes $^{2} \cdot$ César Fonseca $^{2}$. \\ Francisco Gírio ${ }^{2}$
}

Received: 11 December 2017 / Accepted: 10 July 2018

(C) Springer-Verlag GmbH Germany, part of Springer Nature 2018

\begin{abstract}
Purpose The use of bagasse and trash from sugarcane fields in ethanol production is supposed to increase the ethanol yield per hectare, to reduce the energy demand, greenhouse gas emissions, and other environmental impacts. In this article, different technological options of ethanol production are investigated and quantified looking at potential environmental impacts. The firstgeneration ethanol from sugarcane is compared to stand-alone second-generation ethanol as well as an integrated first- and second-generation ethanol production.

Methods The method applied for this life cycle assessment follows the ISO standards 14040/44. The data used in this life cycle assessment is mainly derived from process simulation, literature, and primary data collection. Background data was taken from databases such as GaBi and ecoinvent. The life cycle impact assessment follows the default methods at midpoint level recommended by the International Reference Life Cycle Data System. The calculations were performed using the GaBi 7 life cycle assessment software. It is assumed that $50 \%$ of sugarcane trash is recovered and used for second-generation ethanol production, whereas the other $50 \%$ remain in the field to maintain soil fertility and to prevent soil erosion. In the case of first-generation ethanol, the same amount of trash is used for energy generation.

Results and discussion The results of the life cycle impact assessment show that, compared to first-generation ethanol, secondgeneration ethanol from sugarcane in Brazil allows significant reductions in all investigated impact categories except resource depletion. Resource depletion, however, is strongly influenced by the demand for ammonium phosphate which is needed for inoculum preparation. Integrated first- and second-generation ethanol production also allows reductions in most of the environmental impacts except for global warming, photochemical ozone depletion, and resource depletion. The yield of ethanol per hectare increases since bagasse and trash are used for the production of second-generation ethanol. Consequently, the results show that agricultural land occupation is reduced for integrated first- and second-generation ethanol by approximately $11 \%$, whereas second-generation ethanol allows reduction of land use by approximately a factor of 30 .

Conclusions The use of bagasse and trash for ethanol production allows both the reduction of several environmental impacts and land use, in particular, because impacts caused by sugarcane cultivation are avoided. For the integrated first- and secondgeneration ethanol scenario, it is important to further reduce the total energy demand in order to achieve self-sufficiency for the plant energy and to avoid additional emissions from burning fossil fuels.
\end{abstract}

Keywords Advanced biofuels · Bagasse · Brazil · Ethanol · LCA · Life cycle assessment · Second-generation ethanol · Sugarcane

Responsible editor: Shabbir Gheewala

Electronic supplementary material The online version of this article (https://doi.org/10.1007/s11367-018-1505-1) contains supplementary material, which is available to authorized users.

Daniel Maga

daniel.maga@umsicht.fraunhofer.de

1 Business Unit Sustainability and Resources Management, Fraunhofer Institute for Environmental-, Safety- and Energy Technology UMSICHT, Osterfelder Str. 3, 46047 Oberhausen, Germany
2 Unit of Bioenergy, Laboratório Nacional de Energia e Geologia (LNEG), Estrada do Paço do Lumiar, 22, 1649-038 Lisbon, Portugal 